\title{
EDITORIAL
}

\section{The Mental Strategies of Surgeons: A Primer - Part I}

\author{
Curt Tribble, MD
}

Division of Cardiac Surgery, University of Virginia, Charlottesville, VA, USA

\author{
Part I \\ Introduction \\ Foundations \\ The Hardy Personality \\ Preparation \\ Decision Making

\section{Part II} \\ Vision \\ Awareness \& Focus \\ Reflection \& Analysis \\ Leadership \\ Independence
}

\section{INTRODUCTION}

It is Spring in Virginia, and that means that it is time for medical students to make their final decisions about which discipline of Medicine they will apply to for postgraduate training and to begin their application processes. I have long believed that most medical students with two hands and binocular vision can be successful in a surgical training program, if that is what they choose to do. However, obtaining a surgical residency is a competitive process, which means that the applicants must have their thoughts organized so that they can put their 'best foot forward' as they go through the application and selection process. The most challenging aspects of the application process for virtually everyone are writing personal statements and preparing for interviews, which will be even more complicated than usual, in the midst of the current pandemic. After more than four decades of helping students prepare for these daunting exercises, I have honed the advice that I give these applicants about the related challenges of writing about themselves and of answering questions in interviews. I believe that the candidates must convince the reviewers of their applications that they have, or can develop, the mental strategies necessary to become a capable surgeon. In this treatise, I will outline the mental strategies that I have found essential to achieving

Correspondence: Curt Tribble, MD, Professor of Cardiothoracic Surgery, University of Virginia Health System, Division of Cardiac Surgery, Box 800679, Charlottesville, VA 22908; 434-243-9250 (e-mail: ctribble@virginia.edu). competency in a surgical discipline. The task of the applicants will be, therefore, to assert, with supporting evidence, that they are confident that they have, or can learn, these mental strategies.

In the Part I of this discussion of the mental strategies of surgeons, we will discuss foundations, the hardy personality, preparation, and decision making. In Part II, we will cover vision, awareness and focus, reflection and analysis, and leadership.

Let's get started . . . A few years ago, I had the privilege being in the iconic Grove at The University of Mississippi in Oxford, Mississippi, to hear the well-known author, Walter Isaacson, deliver the 165 th Commencement Address to the graduating seniors of The University of Mississippi. His address was entitled 'What We Forgot To Tell You.' Mr. Isaacson proceeded to explain to the graduates and their guests that, while most learners come into a formal educational environment with certain expectations of what they will learn and take away from that environment, at the end of the whole process what they will, or at least should, take with them upon graduation is more than utilitarian, applied knowledge. Rather, Mr. Isaacson noted, what one should take away are lessons that are less structured and more life enriching, more wisdom than knowledge. He concluded his address with a story about an exchange that had occurred between one of the leaders of his own university and one of his classmates. The professor asked the student "What do you want to be, now that you're leaving college?" The student said "I really want to be successful. I want to be powerful." The professor responded, "Aim higher."

As I myself entered my own surgical residency training, I knew that there was a certain basic set of facts and skills that I would need to acquire to be ready to be a competent surgeon. However, even in my own, relatively naïve, mind I sensed that I would need wisdom, as well as knowledge and technical skills, to be a competent surgeon and, possibly, a surgical educator. I sensed that I would need to learn and understand, and to be able to convey to others, the mental strategies of a capable physician and surgeon. Thus, my search for these lessons began. I wanted to aim higher.

However, before describing what I have learned and taught about mental strategies, I will add some pertinent background. It is not uncommon for people in a variety of fields to be thought of as doers or as thinkers. This kind of dichotomy is almost always erroneous, as the mental and psychological aspects of most activities, performances, or procedures are paramount, even if those aspects are not immediately apparent 
to observers who may be unfamiliar with the challenges of a given activity or performance. The mental strategies required of surgeons may also not be explicitly understood by those immersed in learning the craft of surgery or even, sometimes, by those who teach it.

Despite the fact that I was raised in a surgical environment, with my father having been a Thoracic Surgeon, and despite the fact that I, eventually, chose to pursue training in this realm as well, I found myself slowly, at first anyway, gaining an appreciation of the importance of studying and thinking carefully about the mental strategies of surgeons, as distinct from, though complementary to, accruing factual knowledge and gaining technical skill in this discipline. Eventually, as I became a surgical educator myself, I not only sought to learn more about the mental strategies necessary for good surgical performance but also to learn how to teach these strategies to my protégés, who ranged from medical students and younger residents to the more senior residents and my younger faculty colleagues.

When I was growing up, my father would leave me an occasional newspaper clipping or an article from a magazine or journal he was reading. He would often note, jokingly, that these offerings were in the category of being "for your bathroom perusal." These articles were generally 'era specific,' meaning that, by the time I had started medical school, these articles tended to be about medically related issues, while, earlier in my life, they were about a wider range of topics, from sports to science and from proper word usage to history.

Early in my medical school years, well before I had to choose an area of specialization, one of the articles that my father gave me was an article by Dr. Frank Spencer, a cardiothoracic surgeon who was the Chair of the Department of Surgery at New York University. This article was based on a lecture given at the annual meeting of the American College of Surgeons, which is called 'The Gibbon Lecture' in honor of Dr. John Gibbon, who had been one of the primary pioneers in the development of the heart-lung machine (also known as cardiopulmonary bypass). The lecture was entitled 'Competence and Compassion: Two Qualities of Surgical Excellence.' [Spencer, 1979] In this lecture, Dr. Spencer stated that he believed that great surgical outcomes were dependent much more on judgement and wisdom than on surgical technique or skill. In fact, he even offered his own quantitative breakdown of those issues, asserting that great surgical results are based about $75 \%$ on knowledge, wisdom, and judgement and about $25 \%$ on surgical technique. I read and re-read that lecture for years afterwards. Initially, as a young medical student considering career choices, I was struck by the assertion that surgical results were influenced more by wisdom and judgement than technique, which, at least at that early stage of my own medical trajectory, encouraged me to consider pursuing a career in Surgery, given that, while I could not know whether or not I had the innate technical skill that might have been imbued in only a select few, I did have confidence, based on my own trajectory though life and in school, that it was quite likely that I could learn what I needed to gain the wisdom and judgment described by Dr. Spencer in his Gibbon Lecture. Though I don't recall with complete accuracy everything I considered in making my own final decision to enter surgical training, I am certain that Dr. Spencer's assertions were influential in my ultimate decision to seek training in Surgery. These thoughts also influenced how I approached my own training, once I began my surgical residency and, subsequently, how I approached becoming a surgical educator.

I did eventually, many years later, have the opportunity to meet and to get to know Dr. Spencer. After I told him how much his Gibbon Lecture had influenced my career and confessed that I had written on, highlighted, and spilled coffee all over my only copy of his lecture, the one that my Dad had sent me, he sent me a clean, signed copy of the article that had resulted from his lecture. That article has remained one of my most prized possessions. I have never had a reason, since those days, to change my own opinion that Dr. Spencer was indeed correct about the importance of what I have come to call "The Mental Strategies of Surgeons." In fact, I have dedicated much of my career to thinking, learning, and refining my own thoughts about these mental strategies, while doing my best to convey them to my protégés training in Surgery. I will attempt to convey at least some of what I have learned and taught about these issues in this essay.

I have realized that it is useful to categorize the mental strategies of capable, competent surgeons into more basic categories that many considering careers in Surgery will have some familiarity with, including the foundations needed, the resiliency required, the preparation that is necessary, and the high stakes decision making that will required of them. The more advanced mental strategies that trainees will be expected to learn include vision, awareness and focus, reflection and analysis, and leadership. As noted earlier in this treatise, I will address the basic mental strategies needed to enter training in, and to eventually practice, Surgery, while in a subsequent essay, I will address the more advanced mental skills necessary to become a competent, independent practitioner of the craft of Surgery.

In this pair of essays, I will, of course, draw on my own experiences, those of many that I have counseled and taught, and the lessons I have, very avidly, learned from others, both in medicine and in other realms that require high stakes performance.

\section{FOUNDATIONS: WHY WE DO WHAT WE DO}

It's a truly lucky man who knows what he wants to do in this world, because that man will never work a day in his life. —Carroll Shelby

It is crucial to have a clear idea of why you have committed to doing what you have chosen for your life's work. A practical way to think about this issue is to consider where your energy comes from. For dedicated, elite performers, it is important to have a clear understanding of those sources of energy.

I have often had a retrospective vision where everything in my past life seems to fall with significance into logical sequence. - Ansel Adams 
It is generally true that one's history only seems to make sense in retrospect. That is, most will have formative and influential experiences that, upon reflection, seem to have led to taking the next step in the progression of their lives and careers. Thus, the challenge for these students applying to residencies is to explain how their backgrounds and experiences have led logically to the next stage of their careers. A way of creating such a narrative is to think of presenting their stories as 'throughlines,' in which the story now makes sense while acknowledging that it might not have been preplanned much, if at all.

My own trajectory to medicine, and eventually to surgery, is illustrative of this concept of a throughline. While I myself grew up in a medical family, having been born when my Dad was in medical school, I do not have early memories of being interested in medicine or surgery. Nor did my father ever explicitly encourage me nor my five younger brothers, two of whom are also surgeons, to consider pursuing careers in medicine. However, in retrospect, there were times that, at the very least, prompted me to think about what my future career might be. For instance, I do have a picture from my seventh birthday in which I am sitting at the kitchen table with a doctor's bag and some plastic medical instruments. More pertinently, I also have my first 'op note' which was of a dissection of a frog that my Dad had anesthetized and helped me dissect. As an aside, that experience was my introduction to the necessity of writing an op note, along with some reflections, about every procedure that one has done.

As I continued what turned out to be a 'death defying' childhood, while being aware of what my father did for a living, I do not have a conscious memory of thinking about what I would do when I myself 'grew up.' That remained true, despite having some fairly remarkable experiences tagging along with my Dad to the hospital. One of these experiences was, in retrospect, quite remarkable, and, perhaps, can be seen as an example of a 'throughline.'

When I was about 12, my father and I were on our way home from a college football game, when he was paged to come to the Emergency Room at the hospital where he ran the trauma service. A man had just been brought in with a stab wound to his left chest. As we walked into the trauma bay, the patient's blood pressure fell precipitously. My Dad immediately did an emergency thoracotomy, opening the pericardium, which allowed the heart to fill again, restoring the patient's blood pressure. There was a relatively small wound in the right ventricle on the front of the heart, which was bleeding a bit with each heartbeat. He had the nurses help me don a scrub cap, mask, gown, and gloves and, he then asked me to hold my finger over that wound. He then bounded up the stairs to the operating room to prepare for the repair of the heart and chest wall that would be necessary. The ER team put me on the gurney, with my finger still on the heart, and rolled the patient and me up to the operating room. I had been to the hospital with my Dad before, so the operating room nurses knew my glove size, which were likely the smallest available. They moved the patient into the room, and then they waited to proceed until I had scrubbed (standing on a stool) at the scrub sink and entered the room, ready to be gowned and gloved. Once I was suited up, my Dad repaired the injured ventricle, placed a chest drain, and closed the thoracotomy he had made in the emergency room.

While I did not lie awake at night thinking about this experience in the years that followed, it's hard to imagine that it (and others that were a bit less dramatic) did not have an effect on me. Still, I do recall thinking that all of the folks I encountered in these occasional experiences of going to the hospital and operating with my Dad were somehow able to do complicated things seamlessly and expertly. The data that accrued for me in everything from playing basketball to dealing with my frustrating math classes suggested to me that I was not cut from the same cloth as my Dad and his associates at the hospital. That is, at some relatively vague and immature level, I did not have any sense that I would be capable of doing what they did. In fact, I did not think it would be ethical for me to even think of doing such things. I, therefore, do not recall, at that age, ever contemplating that a career in medicine, and especially in surgery, would be in my future.

There's no heroism in all this. It's a matter of common decency. That's an idea which may make some people smile, but the only means of fighting a plague is common decency. - Albert Camus, The Plague [AJM, 2020]

Six years later I found myself in college. Having always been an avid reader, I was taking English literature classes, generally thinking that I could combine my love of reading and my love of basketball to become, perhaps, a high school teacher and basketball coach. I was at least confident that such a trajectory would not require perfection in thought or action. But, as fate would have it, I eventually found myself in the English class of one the best teachers I have ever encountered, before or since, Dr. James Skinner, and we were reading and studying The Plague by Albert Camus, the French Nobel Laureate. The protagonist in this novel was a physician confronted by an outbreak of the bubonic plague in an Algerian city. While this doctor had the option of leaving the town before it was quarantined, he stayed to care for the people of that city, after sending his family back to France. My own epiphany was that perhaps I would not have to be quite as capable as I had imagined I would need to be in order to contemplate a career in medicine. This evolution of my own thinking led me to decide that I would be both a physician and a teacher, and that I would, eventually, orient my practice around cardiovascular surgery.

I, therefore, look back on formative experiences and exposures such as these as my foundations for pursuing a career in medicine and surgery.

\section{THE HARDY PERSONALITY}

It is apparent that a life of training and practicing in a surgical discipline is challenging and demanding. It is equally apparent that those considering training, or practicing, in a surgical discipline must have, and be able to maintain, the 
energy and resilience to follow this demanding trajectory. For many, these challenges are themselves attractions to enter these fields.

It's supposed to be hard. If it wasn't hard, everyone would do it. The hard is what makes it great. —A League of Their Own

Many people avoid, or even fear, activities or situations that create anxiety while, paradoxically, also frequently seek out activities or situations that result in some degree of arousal. However, many fail to recognize that both of these kinds of situations result in similar physiological states, which are characterized by flushing, tachycardia, and adrenalin release. I learned about this interesting paradox while working with the sports psychologists at The University of Virginia, in the late 1980's. I had adopted a strategy of trying to learn as much about performance and education as I could from many experts in various realms around the grounds of The University during my early years on the faculty, and I realized that I had struck 'a mother lode' when I had the opportunity to get to know the University of Virginia's sport psychologists, led by Dr. Bob Rotella. He showed me an essay that one of his graduate students, Dana Lerner, had written entitled 'The Hardy Personality' that explained the paradox of the overlap of anxiety and arousal. I have found this concept very useful in my work in training medical students and surgery residents ever since. I have used this concept to explain that, in managing the natural emotions accompanying high stakes situations, one can take what is viewed as a negative state to be avoided and channel those feelings into positive energy. While this concept is applicable to emotions experienced 'in the moment,' it is also applicable to the broader idea of 'designing a life' in a high stakes arena, which Surgery most certainly is. In the realm of helping trainees consider their own aptitude for living a life of learning and practicing Surgery, I not only offer this concept but I also ask them to consider their own personalities to see if they believe that they can use this concept to manage their performance in this field.

I believe that man will not merely endure: he will prevail.... because he has a soul, a spirit capable of compassion and sacrifice and endurance. The poet's, the writer's, duty is to write about these things. It is his privilege to belp man endure by lifting his heart, by reminding bim of the courage and honor and hope and pride and compassion and pity and sacrifice which have been the glory of his past. -William Faulkner, Nobel Acceptance Speech, 1950

I have 'channeled' Faulkner's assertions, made in his Nobel acceptance speech, into advising generations of medical students and surgical residents on creating the hardiness and resiliency necessary to practice, and live, in the world of Surgery. In fact, my colleagues and I developed a manual for our students and residents outlining some of the 'minute particulars' of the strategies necessary for living this life. Inspired by Faulkner's famous lines in that Nobel speech, we named this manual 'The Unvanquished,' after one of his best known novels.

A great deal of attention has been appropriately focused in recent years on 'health maintenance,' which, of course, encompasses many aspects of life and work beyond the philosophical underpinnings of why any of us chose to enter a demanding field in the first place. It has become increasingly evident that factors such as compensation or work hours may not have as much impact on performance and resiliency as do other factors such as depersonalization or emotional exhaustion. [Annals of Surgery, 2010] We have written about a variety of strategies that can be used to lessen these potentially debilitating factors [Always Keep Your Clothes in the Car, 2016, and I Call That a Bargain, 2018, Tribble]. These concepts could be described as being part of 'a sustainable design,' a term that I learned from a former Dean of The University of Virginia School of Architecture, Will McDonough. [McDonough, 2003] From the standpoint of an applicant to a Surgery residency, describing one's own innate 'hardy personality' and one's strategies for maintaining one's energy and resiliency will make a powerful case to those selecting candidates for individual training programs.

One illustration of mastering these principles that I have used is one that I learned from teaching novices to sail, and then to race, sailboats. We use fragments of yarn that we put on the shrouds and the sails of these boats to help us 'channel' the wind. When the strips of yarn on the sails are flowing directly back, and not fluttering in a disorganized way, it is evident that one is optimally managing the wind powering the boat. The translation of that concept to a life in a high pressure environment like Surgery is that one must channel the energy, the emotions, and the challenges to optimize the forces, emotional and situational, into productive power for the challenge at hand. One of my favorite quotations about this analogy comes from a book written by a sailor who circumnavigated the globe, single handedly. The following quotation from that book illustrates the channeling of a daunting challenge into a source of energy:

\section{I was born for this moment and for all the days ahead.}

I will find defeat, despair, fear, beauty, serenity, and peace. But before I do, I will be tested far beyond anything I have imagined... In my innocence, I sail on. It is as if the wind were trying to warn me that I am to undergo an ordeal. But I have, I hope, no illusions. I expect an ordeal, an ordeal of grandeur. - Webb Chiles, Storm Passage: Alone Around Cape Horn

As I often do, I asked one of my favorite students to review some of my ruminations about being hardy and resilient. He asked me to add some reflections about handling the death of a patient, which all in medicine and surgery will experience from time to time. He pointed out to me that this subject is rarely, if ever, discussed with medical students and that he believed that this particular issue was one that he felt he would be the least prepared for as a surgical resident. I found myself thinking about this issue at two levels. One is an approach I learned from reading Sir William Osler's speech, given to a graduating class of medical students at Yale, that he entitled 'A Way of Life.' He described an approach that he called "life in day-tight compartments." Osler pointed out in this address that all physicians will inevitably experience, with patients and their families, times of great disappointment, 
sadness, and loss. However, it is equally true that we, those patients' physicians, must be able to continue to function, to care for other patients. He advised that one must be able to find and protect one's piece of mind, or equanimity, in the moment. My own reflection on this advice is that we must not only be able to seek and find solace by compartmentalizing the vicissitudes of our daily practices but that we must also be able to analyze and reflect on what we have done, in order to learn and grow from our experiences. I have used an additional approach, which I liken to 'minimizing' and later 'maximizing' windows on a computer. That is, at times one must be able to put something out of mind in order to be able to continue to function in the moment, while being willing and able to re-examine a decision or a procedure later to learn the lessons afforded by those experiences. I will more fully address some of the strategies for dealing with these situations in Part II of this essay. (Munger, 2014 \& Tribble, 2016)

Finally, I would like to explain a concept related to energy management and the resilience necessary for a life in Surgery that I learned from a Grammy Award winning rock drummer, John Molo. We were traveling together, along with an Olympic gold medalist and a sports psychologist, to conduct a seminar on the mental strategies of performance at a prominent university. Out of the blue, Molo asked the rest of us if we were familiar with a musical concept called 'The Pad.' We all admitted that we were not familiar with that term. He explained that most popular music, from hymns sung in church to rock music, has a 'foundation' that creates energy and comfort which come from a combination, suited to the music and setting, of organ music or drums and which, on balance, is designed to energize the listener and to make them feel good. (A very good example of this concept can be appreciated by listening to 'One Headlight' by Jakob Dylan and The Wallflowers. [Dylan, You Tube]) Molo went on to explain how he used that musical concept in his own life to provide both energy and solace. He described how he loved playing the drums but how he also hated to travel, to be away from his wife and daughter. And, he summarized this thought by saying "I play the drums for free. I get paid to travel. And, I always keep those two things straight in my head." I immediately understood how this concept could be applied to a life in Surgery: I get paid to do paperwork or other things that I don't enjoy, while I operate, write, take care of patients, and teach for free. I have found this concept to be extremely valuable throughout my career as an academic cardiovascular surgeon.

\section{PREPARATION}

By failing to prepare you are preparing to fail. - Benjamin Franklin

Some aspects of preparation in the context of training in Surgery are obvious. There is a relatively agreed upon body of knowledge in Surgery to be mastered, and there is also a standard training paradigm for each branch of Surgery, with defined lengths of those training programs and with specified case numbers and experiences that one must have had during training. However, there are additional aspects of preparation to be considered. One of my most thoughtful colleagues, Dr. Doug Newburg, has said that "having knowledge means you actually know something. However, knowing something is different from knowing about something. The only way to come to know something is through experience and testing, both formal and informal."

Living in a cave does not make you a geologist. Not all practice makes perfect. You need a particular kind of practice - deliberate practice - to develop expertise. . . Genuine experts not only practice deliberately but also think deliberately. - Anders Ericsson

The concept of needing 10 years or 10,000 hours of deliberate practice to be an elite performer, was described many years ago by K. Anders Ericsson, while he was a graduate student, and the concept was re-introduced, years later, by Malcolm Gladwell in 2008 in his book Outliers. [Ericsson, 1993 \& Gladwell, 2008] It is worth noting that Dr. Ericsson consistently emphasized that this practice needed to be deliberate practice, by which he meant that these hours must be 'logged' both with proper coaching and with proper contemplation and reflection complementing the actual practice. These numbers do correlate fairly closely with the length of formal training programs in Surgery, particularly if one includes the clinical years of medical school, the usual years of surgical training, and the first few years of independent practice, each with their own specific learning curves.

Moving from the general preparation of a training program to the specific setting of preparing for a specific operation, either as a trainee or as a practicing surgeon, one must prepare thoroughly for that specific patient and the particular operation being contemplated. [Tribble: Failing to Prepare, 2016] However, one must also prepare for unusual situations that one has yet to encounter. As a junior resident, I was involved in the care of a patient who had undergone a complex head and neck cancer operation. The patient was losing his airway as the edema in his oropharynx worsened, and he was becoming increasingly hypoxic. I was sent to try to get him intubated, but the swollen, abnormal tissues made that task daunting, so I called the anesthesiologist who had cared for the patient during his recent operation. He, likewise, was unable to visualize the anatomy and, with the patient becoming increasingly hypoxic, I called the Chief Resident who had participated in the original operation. He asked me to have a central line kit with a guidewire ready when he arrived. When he made it to the room, he immediately put the needle into the trachea in the lower neck, inserted the guidewire, and asked me to grab it with a clamp when it became visible in the patient's pharynx. I was able to do that and asked what I needed to do next. He told me to thread the wire through the endotracheal tube and to then push the tube into the pharynx over the wire, which we were holding taut at each end. As the tube entered the upper trachea, he slowly pulled the wire out. We inflated the balloon cuff of the tube and gave the patient a breath with an Ambu bag. The chest rose and fell appropriately, and the patient's color quickly shifted from blue to pink. The Chief Resident stood up, shot his gloves into a trash 
can with a flourish, and turned to head back to the operating room. The attending anesthesiologist asked, "Steve, have you ever done that before?" His answer, which was priceless and unforgettable, was "no, but I've thought about it a lot." The lesson was, of course, not lost on any of those present. One must prepare not only for the situations that commonly occur, but one must also prepare for situations that one might one day encounter, preparation that one must do in anticipation that such preparation could mean the difference between life and death.

Another type of preparation is that required to carry out a complex operation with a large team. After we had established our lung transplant program at the University of Virginia in the early 1990's [Tribble, 1991], we began to be referred children that needed lung transplants. There were, however, very few pediatric lungs available for donation. Therefore, we decided to move into the relatively new realm, at the time, of using living donors to address this need. The approach required for this type of donation and transplantation is to identify two healthy adults willing to donate a lobe of one of their lungs to allow for a double lung transplant for a child. In our first transplant of this sort, two healthy adult men each volunteered to donate a lobe of one their lungs to the small child in need of a double lung transplant. Although our team had, by this time, accrued a lot of experience with lung transplantation in adults, the planned operation would be the first time any of us in our group would be caring for three patients at once to accomplish a lung transplant. In addition to extensive preparation in the days and weeks leading up to the planned operation, on the morning of that operation I had everyone who would be involved in the three operative teams gather in a classroom near the operating room to review every step of all three operations. We set aside an hour for this final briefing prior to starting these procedures. We planned to remove the left lower lobe from one of the donors and the right lower lobe from the other. We would be removing the left lung of the recipient as our colleagues removed the left lower lobe from one of the donors, and then, as soon as that lobe was removed, we would implant it in the left side of the child's thorax. And, of course, we would repeat that process with the right lower lobe of the second donor. As we finished our hour long briefing session, while feeling as comfortable as was reasonable with these plans, I turned to the group and said "Today is the first time any of us have been involved in an operative process in which it is conceivable that three patients could die." While that was a somber note with which to conclude our session, it was, indeed, a fact. However, with our careful planning and coordination, all three patients did well and were eventually discharged to home, doing well.

On a more mundane level, one must, of course, be as fully prepared for each procedure or operation that one is planning to do as it is possible to be. This type of preparation is more straightforward and obvious and includes being familiar with the patient, the information about that patient, the procedure being contemplated, and the possible problems that might arise while conducting that procedure.
In summary, one must prepare deliberately for the situations and procedures that one expects to do, and one must prepare, as well, for unexpected and unusual situations.

\section{DECISION MAKING}

There is no greater teacher of life than the practice of medicine but none greater than the place where life and death are most precariously balanced. - Haider Warraich, MD [Warraich, 2016]

When I ran the Surgery Clerkship for medical students at the University of Virginia for the better part of two decades, I gave a number of lectures to each group of medical students rotating through Surgery, some practical and detailed, some abstract and philosophical, and some that fell in the middle of this range. One of those lectures that fell in this middle range was about decision making in surgery.

I started each of these lectures with a question: "Who in the class has ever taken a course on decision making, read a book on the subject, or even had a single lecture prior to, or even in, medical school on decision making?" Of the literally thousands of UVA medical students who sat in those classes, not one ever raised their hand. Ever. I then gave at least a few of them 'an out,' by saying "Well, who here has taken a class in Logic?" Three or four times a year, at the most, someone would raise their hand. Then I would ask if anyone in the class had majored in engineering in college. An occasional student would raise their hand, saying that they had, indeed, been an engineering major, and I would acknowledge that the training of engineers is largely about decision making. Still, that left the vast majority of these students realizing that they had never had any formal instruction in decision making during their educational trajectories. I would then say, "Well, today I will offer some thoughts on decision making for your consideration, particularly decision making in Surgery."

As an aside, I will admit that there are very sophisticated articles and books on decision making in medicine, some of which specifically address decision making in Surgery. Some of these treatises do provide some excellent insights and suggestions. However, even these treatises have their limitations. [McIntyre \& Schulick, 2020] Here, I will focus more on the basics of decision making, as filtered through the mind of someone who has studied, practiced, and taught medicine and surgery for decades. I will not delve into sophisticated statistical approaches nor computer assisted strategies, though both of these approaches to decision making do have much to offer. [Brush, 2015] Rather, I will dwell more on some basic aspects of making decisions, as surgeons often must, in the setting of time and information constraints and while under other types of pressure as well.

Can you learn to make your first reaction the best response even if, especially if, the best response is a question, which it often is? Doug Newburg, $\mathrm{PhD}$

One way of adding structure to decision making can be to ask questions and to brainstorm about options, while considering as many possibilities as feasible. One approach to 
adding structure to decision making that is readily apparent to surgeons is an anatomical one, as illustrated in Cope's Early Diagnosis of the Acute Abdomen. In this venerable book, originally written by Sir Zachary Cope and later updated by Dr. William Silen, the reader is counseled to organize diagnostic and therapeutic considerations based on the pertinent anatomy. [Silen, 2005] In the case of a patient with an acute abdomen, one would obviously consider each organ system of the abdomen to give proper thought to which, if any, of these organ systems was the likely source of a patient's problems. I have used a similar thought process when seeing patients with leg pain, usually sent for consideration of arterial abnormalities but often having some alternate explanation of their symptoms, which could arise from the nerves, muscles, joints, bones, or the veins of the leg. An analogous structure can be employed in thinking about a critically ill patient, which is to consider each organ system in the body, one at a time. [Tribble, 2009] I have found it useful in some situations of this sort to take out a piece of paper (or to use a white board) and to write out each organ system, what is known about that organ system at the time, and what might need to be done for or learned about each of these organ systems. In other words, this approach will allow a health care team to brainstorm, while breaking down the data and the actions that might be needed into smaller areas. This approach to organizing information to make decisions about complex patients can be invaluable.

There are a number of useful questions that can be asked to foster collaborative brainstorming and decision making. One simple one can be 'wait, what?' [Ryan, 2017] Obviously, this question intimates that the listener does not completely understand a statement or plan, but is ready to hear more about the subject. Another disarming question in these situations can be some variation on the theme of 'What might I be missing?' or 'What are you seeing that I am not?' And, a different kind of question to foster discussion in an unthreatening way is 'What would it take to change your mind?' [Stillman, 2020] Another similar question is to ask 'What might be true of that?' [Elgin, 1985] One can also ask, at least rhetorically, 'What is it you want to have happen?' or 'What is the worst thing that can happen if we take this or that course?'

Many decisions in surgery are time sensitive, and, because of that constraint, some decisions may have to be made with incomplete information. An example of this kind of thinking is seen in the work of fire fighters. For instance, a fire chief is said to have to 'look through two windows at once.' One 'window' is to see, or think about, what appears to be happening, while the other is to envision what might happen next. [Buckman, 2019]

One of my primary mentors from my days of training, Dr. Stanton Nolan, used to teach us that a cardiac surgeon makes a potentially life or death decision about every 10 seconds during a cardiac surgical operation. However, while there are indeed many situations in which rapid decisions must be made and swift action taken, this type of thinking can lead to an inappropriate overreliance on heuristics, which can introduce cognitive bias to the thought processes. In other words, while one must always be thinking about what might need to be done next, one must also employ a sort of secondary 'review' to avoid an inappropriately reflexive decision. Obviously, one defense against this kind of cognitive error is to empower those with whom you work to speak up if they are seeing things differently or if they have other suggestions about what the optimal approach might be. The pitfalls of using axioms or heuristics have been very well described by the Nobel Laureate, Daniel Kahneman, in his book Thinking Fast and Slow. In this book, Dr. Kahneman discusses, in great depth, many of the pitfalls, or biases, that we humans are quite prone to, such as anchoring biases. [Kahneman, 2011]. There have been some excellent extrapolations of Dr. Kahneman's admonitions to the realm of surgical decision making. [Hughes, 2020]

Another way of adding structure to decision making can be through the use of checklists. The first time that I was introduced to checklists was in flying small planes with my Dad when I was young. I remember vividly his handing me a laminated card with 14 bullet points on it and asking me to read it to him. But, before I could start reciting the list on the card, he asked me "Why do you think I want you to read me that list?" After a moment of contemplation, I said "I guess it's because it's hard to remember all 14 things on this list." $\mathrm{He}$ replied, "Bingo! Of course it's hard to remember all 14 things, at least for us mere mortals!" I never forgot that important lesson and have subsequently written about the use of checklists in Surgery. [Calland, 2002]

At the end of the day, good outcomes may be more dependent on asking the right questions than they are on knowing the right answers. In fact, we like to point out that the answers may change over time or with different situations, but the questions are timeless. Therefore, we often tell our trainees that our primary job as their mentors is to teach them the questions that they should be asking themselves. And, to be even more granular, the best decision makers learn to ask themselves the right questions, in the correct order, using the optimal increments. [Blackbourne, 2018]

However, sometimes, when there does not seem to be a right answer to the question being posed, a useful strategy can be to change the question. This bit of wisdom is well illustrated by an episode in one of the Star Trek movies [Stemwedel, 2015]. In this story, James Kirk, as a cadet in the Starfleet Academy, was faced with an ethical choice on his final exam at The Academy. Knowing that all prior cadets had failed the exam, which involved choosing between two impossible scenarios, Kirk changed the question, thus becoming the first Starfleet cadet to answer the question successfully. While there has been considerable discussion by Star Trek fans about the propriety of changing a question in order to pass an exam, the scenario does provide a valuable lesson in decision making, which is: If you don't know the answer, consider changing the question.

Good decision making is generally not facilitated, at least in real time, by decision making algorithms, though such algorithms can help one learn about the decision making process for certain specific situations, as illustrated by the insightful book entitled Surgical Decision Making, originally written by Dr. Ben Eiseman and later updated by his 
successors at the University of Colorado. [McEntyre, 2020] I have found these decision making books to be useful for studying for exams but not nearly as useful for making decisions about a specific patient or situation. To be more specific, it is important to realize that optimal decision-making is often not accurately compressed into algorithms. An algorithm is a diagram in which each decision point usually has only two choices. Decision making in medicine very rarely involves choosing between only two courses of action. There are almost always more than two choices 'in play' and attempts to put medical decision making into 'if this, then that' types of decision trees ultimately may not provide the best outcomes for our patients. I believe, alternatively, that decision making is more like a polynomial equation of the type that we all learned about in advanced algebra. The following is an example of a polynomial equation in which the letters are constants and the other factors are raised to different powers:

$$
\mathrm{Ax}^{4}+\mathrm{Dx}^{3}+\mathrm{Cx}^{2}+\mathrm{Dx}+\mathrm{E}=\text { Decision }
$$

I believe that this example better illustrates the way decisions are, or should be, made. Different factors have different levels of importance (as denoted by the exponents), and they also have different degrees of likelihood (as denoted by the letters). All of these factors must be taken into account before a decision is made. Also, some of these varying levels of likelihood and of importance and consequence will change depending on patient related factors such as their personal preferences or their religious beliefs, as well as on hard and fast medical or technical issues.

This concept can be illustrated by a story of a patient who presented to our Emergency Room many years ago with abdominal pain and microscopic hematuria. The resident who saw the patient was able to palpate what he thought was a small abdominal aortic aneurysm. He reasoned, since people in our region have a lot of kidney stones and since the patient had microscopic hematuria (as commonly occurs with kidney stones), that the patient most likely had a kidney stone, and he sent the patient out with some pain medicine, telling him to drink plenty of water. The patient returned to the ER later that night, in extremis, with a ruptured abdominal aortic aneurysm. In reviewing this scenario with that resident I said, "You were right in thinking that kidney stones are common and that this patient's presentation was typical of a patient with a kidney stone. Where you erred was in NOT thinking 'what is the worst or most ominous thing that the patient might have?' If you had thought that way, there's a good chance we could have saved that patient." So, that night, likelihood trumped consequence to the detriment of that patient. The take-home message, of course, is that one must put more weight on the consequence of a possible diagnosis than on the likelihood of that diagnosis. No one dies of a kidney stone, but people with leaking aortic aneurysms often do.

Like other elite performers, a surgeon must also learn to make decisions with incomplete information. One must take into account the potential need for more information and balance that against the urgency of the situation and, when the occasion demands it, be ready to move ahead even when all the information is not known.

There is often, for skilled clinicians, an 'aha' moment. It is understood that a computer can't 'get' a joke. —Charles Abernathy, in Surgical Intuition [Abernathy, 1995]

Similarly, despite the obvious power of computers to do calculations and to make information available at the stroke of a key or two, computers are generally quite limited in making decisions, especially 'on the fly.'

If feel a responsibility ... to teach that doubt is not to be feared, but that it is to be welcomed as the possibility of a new potential. - Richard Feynman, in The Freedom of Finding Things Out [1999]

While it is easy to admire clinicians who seem self-assured, it is important to remember that the best clinicians will always be second guessing themselves, especially when time permits further contemplation.

Therefore, you must have a sense of what you really know, develop a comfort level with being able to doubt, understand the balance of likelihood and risk, be able to deal with time constraints, and put your focus on learning to ask the proper questions for a given situation.

A problem solving strategy that is taught in engineering classes can be useful to physicians and surgeons. First, one must clearly identify the problem to be solved. In engineering, that process would include defining the parameters and constraints pertinent to the issue at hand. In medicine and surgery the question should turn to defining clearly what the desired outcome should be. Once the problem is clearly identified, potential solutions should be considered. This stage of decision making can be referred to as the brainstorming stage. When using this approach, one should encourage all involved to think of all potential solutions to the question at hand, no matter how far-fetched they may seem at first. This approach encourages freedom of thought. In medicine and surgery, the ultimate solution to a difficult problem is often a combination of things that were considered, at first, to have been 'on the lunatic fringe.' The last step in this process is to formulate the ultimate solution to be applied, at least at that particular point in the decision making process. In summary, choosing the optimal strategy in a given clinical situation often requires including all the available information and advice, regardless of whose 'gut' or brain provided it.

As one struggles with a particular decision, advice from thoughtful colleagues should be sought. Advice from shallow thinkers is often of little value. Some have suggested a structure or nomenclature for such decisions which can be described as first level, second level, third level, and fourth level thinking or decision making. The fourth level is obviously the ultimate level of decision making. Only the person who has to make the ultimate decision is truly capable of making that fourth level decision. For instance, the attending surgeon is the person who must decide if a particular patient should be offered an operation or when to accept the results of a cardiac operation and wean from cardiopulmonary bypass. 
The shallow thinking advisor can reach a decision with, or for, you. A more thoughtful, or secondary, advisor might be someone who does not quite grasp all of the issues involved and can give you some thoughts at this secondary level. An even more thoughtful and savvy consultant may be able to offer the tertiary level of advice. However, only the physician who must make the final decision can reach the fourth or quaternary level of decision making. This person will be the one who knows the social, professional, medical, and personal capabilities, backgrounds, and priorities of both the physician and the patient. Decisions made at this level should be arrived at only with a great deal of effort and thought.

Perhaps the most challenging decisions in which I myself have participated over most of my career have been those that our transplant selection committees (both lung and heart selection committees) have had to make on a weekly basis. While it is generally apparent that the decisions made in these committees have important ramifications for the specific patients being discussed, they also, in a more abstract sense, affect patients who might, at least theoretically, not be able to receive one of these scarce organs, given that there are always more potential recipients than there are donor organs available. A memorable example of one of these discussions involved a dentist who was being evaluated for a lung transplant by our selection committee. It has always seemed that most potential recipients have some kind of concerning or limiting issue that requires a lot of thought and consideration. The issue in this patient's case was that he seemed to have some type of bone marrow suppression, which, we concluded, would limit our ability to administer the necessary anti-rejection medications. When we conveyed our concerns to the patient, he said: "Since you think that I won't be able to tolerate those medications, why don't you just start me on them and find out?" We noted that his insurance would not cover the cost of the medications, if he had not had a transplant. His response was: "What if I pay for them myself, so that we will know, one way or the other?" We acknowledged that this idea did make some sense and agreed to that plan, as unusual as it was. It turned out that the medications used in this 'trial run' did not cause untoward side effects, and we did, indeed, eventually do a lung transplant for him, which turned out successfully. This case reminded us all of the necessity of not only brainstorming in our own group but also of the value of open discussion with the patient.

Finally, in discussions of medical decision making, I often say that surgeons are gamblers and must, therefore, have some sense of the odds of almost everything that might happen in a given situation. Even when one does not know the exact odds, it is sometimes useful to try to calculate a rough estimate of the odds of certain events occurring. [Duke, 2018] Overall, however, we know that perfection under most conditions is virtually unattainable. In fact, one of our sayings is that "perfection is the enemy of good." After all, if one waits until all possible information is available, hoping that perfection in the decision making process can be achieved or even approached, one may come to a perfect decision but end up with a dead patient.

\section{End of Part I}

In this first of two 'installments' of 'The Mental Strategies of Surgeons' we have reviewed Foundations, The Hardy Personality, Preparation, and Decision Making. In the second 'installment' we will review Vision, Awareness \& Focus, Reflection \& Analysis, Leadership, and Independence.

\section{ACKNOWLEDGEMENTS}

I would like to acknowledge the following for significant contributions to the concepts presented in this essay, including Doug Newburg, Robert Hannan, Robert Rotella, Reid Tribble, David Tribble, John Molo, Clifton Meador, Stanton Nolan, Alex Michaels, and James Keiler, as well as many mentors, friends, and trainees.

\section{REFERENCES}

Spencer F. 1979. Competence and Compassion: Two Qualities of Surgical Excellence. Bulletin of the American College of Surgeons. November 1979: $15-22$

Shelby C. 2019. Ford versus Ferrari. https://www.moviequotesandmore. com/ford-v-ferrari-best-movie-quotes/ (Accessed September 23, 2020)

Adams, Ansel. Goodreads.com. https://www.goodreads.com/quotes/ 141663-i-have-often-had-a-retrospective-vision-where-everything-in (Accessed July 1, 2020)

Alpert J. 2020. 'A plague o' both your houses:' Selected Quotations for Our Times. Am J Med 133: 647.

A League of Their Own. https://www.espn.com/espnw/w-in-action/2015summit/story/_id/13835992/5-best-quotes-league-their-own (Accessed July 1, 2020)

Faulkner W. Banquet Speech. NobelPrize.org. Nobel Media AB 2020. https://www.nobelprize.org/prizes/literature/1949/faulkner/speech (Accessed July 1, 2020)

Shanafelt T, Balch C, Bechamps G, Russell T, Dyrbye L et al. 2010. Burnout and Medical Errors among American Surgeons. Ann Surg 251: 995-1000.

Tribble C. 2016. Always Keep Your Clothes in the Car. Heart Surg Forum 19: 237-40.

Tribble C. 2018. I Call That A Bargain. Heart Surg Forum 21: 237-40.

McDonough, W. 2003. Principles, Practices, and Sustainable Design. https://mcdonough.com/writings/principles-practices-sustainabledesign/ (Accessed July 14, 2020)

Webb Chiles. 1977. Storm Passage. New York Times Books. New York, NY.

Munger, C. 2014. Sir William Osler: A Way of Life. https://fs.blog/2014/07/ william-osler-a-way-of-life/ (Accessed July 21, 2020)

Tribble C. 2016. A Practical Minded Obsession with the Possibility and Consequence of Failure. Heart Surg Forum 19: E001-E004.

Dylan J. One Headlight. https://www.youtube.com/ watch?v=Zzyfcys1aLM (Accessed July 1, 2020)

Tribble C. 2016. Failing to Prepare is Preparing to Fail. Heart Surg Forum 19: E112-5. 
Ericsson K. 2007. The Making of an Expert. Harvard Business Review. July-August 2007 Issue.

Ericsson K, Krampe R, Tesche-Romer C. 1993. The Role of Deliberate Practice in the Acquisition of Expert Performance. Psychological Review 100: 363-406.

Gladwell M. 2008. Little, Brown and Company. Boston.

Tribble C, Kern J, Findley L, et al. 1991. The First Single Lung Transplant in Virginia. Virginia Medical Quarterly 118: 166-7.

Warraich H. 2016. Lessons in Life: As Taught by the Cath Lab. Circulation 134: 1125-6

McIntyre R, Schulick R. 2020. Surgical Decision Making, 6th Edition. Elsevier, Philadelphia, PA.

Brush JE. 2015. The Science of the Art of Medicine, 2nd Ed, Pathway Book Service, Keene, NH https://www.medscape.com/viewarticle/852124 (Accessed July 15, 2020)

Silen W. 2005. Cope's Early Diagnosis of the Acute Abdomen, 21st Edition. Oxford University Press, New York, NY.

ICU Recall. Third Edition. 2009. Tribble C, Hobson C, Thaemert N. Wolters Kluwer Health / Lippincott, Williams \& Wilkins. Baltimore.

Ryan, J. 2017. Wait, What? And Life's Other Essential Questions. Harper Collins Publishers. New York.

Stillman, J. 2020. https://www.inc.com/jessica-stillman/google-chiefdecision-scientist-ask-this-question-before-every-big-choice.html (Accessed September 23, 2020)

Elgin S. 1985. The Gentle Art of Verbal Self-Defense. Dorset House Publishing Co, Inc. New York.

Buckman J. 2019. Anatomy of fireground decision-making. https://www.firerescue1.com/cod-company-officer-development/articles/anatomy-of-fireground-decision-making-1qXooer8HDzAQmZp/ (Accessed July 10, 2020)

Kahneman, D. 2011. Thinking Fast and Slow. Farrar, Straus and Giroux. New York.

Hughes T, Dossett L, Hawley S, Telem D. 2020. Recognizing Heuristics and Bias in Clinical Decision-making. Ann Surg 271:813-4.

Calland J, Guerlain S, Adams R, Tribble C, Chekan E. 2002. Surg Endosc 16: $1005-14$.

Blackbourne L. 2018. Surgical Recall. Wolters Kluwer. Baltimore.

Stemwedel J. 2015. The Philosophy of Star Trek: The Kobayashi Maru, No-Win Scenarios, and Ethical Leadership. Forbes. https://www.forbes. com/sites/janetstemwedel/2015/08/23/the-philosophy-of-star-trek-thekobayashi-maru-no-win-scenarios-and-ethical-leadership/\#6d5314255f48 (Accessed 6-17-20)

Abernathy C, Hamm R. 1995. Surgical Intuition: What It Is and How to Get It. Hanley \& Belfus, Inc. Philadelphia.

Feynman R. 1999. The Pleasure of Finding Things Out. Perseus Publishing. Cambridge, MA.
Duke, A. 2018. Thinking in Bets. Portfolio/Penguin. New York, NY.

\section{ADDITIONAL REFERENCES}

Newburg D. 2009. The Most Important Lesson No One Ever Taught Me. Xlibris Corporation. Bloomington, IN.

Crawford M. 2006. Shop Class as Soulcraft. The New Atlantis: A Journal of Technology and Society. www. TheNewAtlantis.com (Accessed July 10, 2020)

Meador C. 2020. A Little Book of Doctors' Rules. Square One Publishers. Garden City Park, NY. ISBN 9780757004933

London, O. 1987. Kill as Few Patients as Possible. Ten Speed Press. Berkeley, CA.

Jacobs, A. 2017. How to Think: A Survival Guide for a World at Odds. Currency, an imprint of Crown Publishing Group, Penguin Random House. New York, NY.

Kruger J, Dunning D. 1999. Unskilled and Unaware of It: How Difficulties in Recognizing One's Own Incompetence Lead to Inflated SelfAssessments. J Personality and Social Psychology. 77 (6): 1121-34.

Ahmed O, Walsh T. 2020. Surgical Trainee Experience with Open Cholecystectomy and the Dunning-Kruger Effect. J Surg Ed, in press. https://doi.org/10.1016/j.jsurg.2020.03.025

Noronha V. 2020. The Day My Gut Feeling Led Me Astray. N Engl J Med 382: 1880-1.

Krinsley J, Reddy P, Iqbal A. 2012. Case-control study of failed extubation. Critical Care 16: 128.

Lovell B. August 2017. The Resilience Paradox. J Grad Med Ed. DOI: http://10.4300/JGME-D-16-00709.1

Wallace DF. 2009. This Is Water: Thoughts, Delivered on a Significant Occasion, about Living a Compassionate Life. Little, Brown and Company. New York.

Sade R. The Ethics of Surgery. 2015. Oxford University Press. New York

Orwell G, Packer G. 2008. Facing Unpleasant Facts. Houghton Mifflin, New York.

McRaven W. 2017. Make Your Bed: Little Things That Can Change Your Life ... And Maybe The World. Hachette Book Group. New York.

Ravitch M. 1987. Second Thoughts of a Surgical Curmudgeon. Mosby. Maryland Heights, MO.

Gladwell M. 2013. Complexity and the Ten-Thousand-Hour Rule. The New Yorker. https://newyorker.com/sports/sporting-scene/complexityand-the-ten-thousand-hour-rule (Accessed July 14, 2020)

Botterill C, Brooks J, Hussain A. 2018. Sustainable High Performance. Premier Printing, Ltd Manitoba, Canada

The Plague, from Goodreads: https://www.goodreads.com/quotes/84490there-s-no-question-of-heroism-in-all-this-it-s-a (Accessed July 10, 2020) 